\title{
Leitos de UTI dedicados à COVID-19 e medidas de contenção do vírus no Estado de
}

\section{Goiás}

\author{
ICU beds dedicated to COVID-19 and virus containment measures in the State of Goiás \\ Camas de UCI dedicadas al COVID-19 y medidas de contención del virus en el Estado de Goiás
}

Recebido: 06/09/2021 | Revisado: 15/09/2021 | Aceito: 19/09/2021 | Publicado: 20/09/2021

\author{
Pietro Alessandro Vaccario \\ ORCID: https://orcid.org/0000-0002-4093-8330 \\ Pontifícia Universidade Católica de Goiás, Brasil \\ E-mail: vaccariopietro@gmail.com \\ Eleonôra Campos Adriano da Silva \\ ORCID: https://orcid.org/0000-0002-5493-9449 \\ Pontifícia Universidade Católica de Goiás, Brasil \\ E-mail: eleonoraadrianonutri@gmail.com \\ Joana Campos Adriano da Silva \\ ORCID: https://orcid.org/0000-0001-8677-7168 \\ Universidade da Associação de Ensino de Ribeirão Preto, Brasil \\ E-mail: joanacadriano@gmail.com \\ Edna Joana Cláudio Manrique \\ ORCID: https://orcid.org/0000-0002-8632-3542 \\ Pontifícia Universidade Católica de Goiás, Brasil \\ Laboratório Estadual de Saúde Pública Dr. Giovanni Cysneiros, Brasil \\ E-mail: ednamanrique@gmail.com
}

\begin{abstract}
Resumo
Objetivo: Descrever o cenário de ocupação dos leitos de UTI dedicados à COVID-19 no período próximo ao carnaval e as medidas adotadas para a contenção do vírus, no estado de Goiás. Metodologia: Trata-se de um estudo retrospectivo, observacional e descritivo. Foram usadas as taxas de ocupação de leitos de UTI destinados à COVID19, por região no estado de Goiás retiradas dos mapas de riscos de 17, 27 e 05 de março de 2021; além de decretos e normas desde 11 de fevereiro a junho de 2021, retirados do Portal da SES-GO e Casa Civil de Goiás. Resultados e Discussão: A média das taxas de ocupação de leitos de UTI aumentou cerca de $12 \%$ após o carnaval. Março foi considerado pela mídia o pior mês da pandemia até então, devido à variante P1. Entre as medidas de contenção do vírus, decretos e normas foram emitidos, mas dá-se destaque à crescente distribuição e aplicação de vacinas, o que trouxe um cenário mais favorável em junho. Conclusão: Durante o período próximo ao carnaval, cresceram as taxas de ocupação de leitos de UTI, em Goiás. Entre as medidas, nota-se distanciamento físico, realocação de leitos, higienização das mãos, o uso de máscara e a vacinação.
\end{abstract}

Palavras-chave: Unidade de Terapia Intensiva; COVID-19; Distanciamento físico; Vacinação.

\begin{abstract}
Objective: To describe the occupation of ICU beds dedicated to COVID-19 in the period close to Carnival and the measures taken to contain the virus in the state of Goiás. Methodology: This is a retrospective, observational and descriptive study. Occupancy rates of ICU beds destined to COVID-19 were used, by region in the state of Goiás, taken from the risk maps of March 17, 27 and 5, 2021; in addition to decrees and norms from February 11 to June 2021, taken from the SES-GO Portal and the Civil House of Goiás. Results and discussion: The average ICU bed occupancy rates increased about $12 \%$ after Carnival. March was considered by the media as the worst month of the pandemic so far, due to the P1 variant. Among the virus containment measures, decrees and norms were issued, but the growing distribution and application of vaccines is highlighted, which brought a more favorable scenario in June. Conclusion: During the period close to Carnival, ICU bed occupancy rates increased in Goiás. Among the measures, there was physical distance, relocation of beds, hand hygiene, the use of masks and vaccination.
\end{abstract}

Keywords: Intensive Care Units; COVID-19; Physical distancing; Vaccination.

\section{Resumen}

Objetivo: Describir la ocupación de camas de UCI dedicadas al COVID-19 en el período cercano al Carnaval y las medidas tomadas para contener el virus en el estado de Goiás. Metodología: Estudio retrospectivo, observacional y descriptivo. Se utilizaron las tasas de ocupación de las camas de UCI destinadas al COVID-19, por región en el estado de Goiás, tomadas de los mapas de riesgo del 17, 27 y 5 de marzo de 2021; además de los decretos y normas del 11 de 
febrero a junio de 2021, tomados del Portal SES-GO y de la Casa Civil de Goiás. Resultados y Discusión: Las tasas promedio de ocupación de camas en UCI aumentaron alrededor del 12\% después del Carnaval. Marzo fue considerado por los medios como el peor mes de la pandemia hasta el momento, debido a la variante P1. Entre las medidas de contención de virus se emitieron decretos y normas, pero se destaca la creciente distribución y aplicación de vacunas, lo que trajo un escenario más favorable en junio. Conclusión: Durante el período cercano al Carnaval, las tasas de ocupación de camas de UCI aumentaron en Goiás, entre las medidas se destacó distancia física, reubicación de camas, higiene de manos, uso de mascarillas y vacunación.

Palabras clave: Unidades de Cuidados Intensivos; COVID-19; Distanciamiento físico; Vacunación.

\section{Introdução}

A COVID-19 é uma doença que tem como causa o novo coronavírus nomeado de SARS-CoV-2. Ela foi detectada pela World Health Organization (WHO), após relatada uma sequência de casos de "pneumonia viral" na cidade de Wuhan, localizada na República Popular da China, em dezembro de 2019 (WHO, 2020a). No dia 31 de janeiro de 2020, a WHO determinou o estado de Emergência em Saúde Pública de Interesse Internacional devido ao incremento acelerado no número de óbitos na China (WHO, 2020b). Em 11 de março de 2020 foi determinada pandemia mundial pela própria organização (WHO, 2020c).

Em 20 de março de 2020, foi declarada a transmissão comunitária da COVID-19 em todo o território Brasileiro (Brasil, 2021a). No estado de Goiás, desde os primeiros registros de casos suspeitos da COVID-19, em 04 de fevereiro de 2020, até 13 de fevereiro de 2021 foram notificados à Vigilância Epidemiológica 1.063.329 casos (SES-GO, 2021a).

O Governo de Goiás teve de suspender o feriado de terça-feira de carnaval, 16 de fevereiro de 2021, para evitar aglomerações (Goiás, 2021a). De 14 a 20 de fevereiro foram notificados 1.109 novos casos de (Síndrome Respiratória Aguda Grave) SRAG pela COVID-19, 27,3\% a mais do que na semana anterior (871 casos); já na última semana de fevereiro os casos notificados caíram 25,7\%, totalizando 824 novos casos de SRAG por COVID-19 (SES-GO, 2021b, 2021c).

A infecção pelo SARS-CoV-2 pode gerar desde casos assintomáticos ou com manifestações clínicas leves a casos graves e críticos. Casos graves são aqueles que apresentam SRAG, ou seja, quadros de Síndrome Gripal associados a dispneia e/ou desconforto respiratório e/ou pressão persistente no tórax e/ou saturação de oxigênio menor que $95 \%$ e/ou coloração azulada de lábios ou rosto. A Síndrome Gripal trata-se e um quadro respiratório agudo, caracterizado por dois ou mais dos seguintes sintomas: febre aferida ou referida, calafrios, dor de garganta, cefaleia, tosse, coriza, distúrbios olfativos ou gustativos. Casos Críticos são aqueles cujos principais sintomas são: sepse, síndrome do desconforto respiratório agudo, insuficiência respiratória grave, disfunção de múltiplos órgãos, pneumonia grave, necessidade de suporte respiratório e internações em Unidades de Terapia Intensiva (UTI) (Brasil, 2021a).

Pelo protocolo de regulação de internação e de Urgência e Emergência para a COVID-19 (Goiás, 2021b), revisado em março de 2021, as indicações de internação em UTI seguem o Protocolo de Influenza. Essas são: instabilidade hemodinâmica persistente (pressão arterial que não respondeu à reposição volêmica (30 mL/kg nas primeiras 3 horas), indicando uso de amina vasoativa (exemplo: noradrenalina, dopamina, adrenalina); sinais e sintomas de insuficiência respiratória, incluindo hipoxemia ( $\mathrm{PaO} 2$ abaixo de $60 \mathrm{mmHg}$ ) com necessidade de suplementação de oxigênio para manter saturação arterial de oxigênio acima de 90\%; e evolução para outras disfunções orgânicas, como insuficiência renal aguda e disfunção neurológica (Brasil, 2018b).

Nos locais com maior disseminação do vírus, espera-se um crescimento rápido na demanda por serviços de saúde. Entre eles, leitos de UTI para suporte nos quadros de SRAG. Parte da comunidade científica, já em 2020, apontava a necessidade de identificar regiões mais vulneráveis, otimizar o uso de serviços existentes e dimensionar recursos necessários para fortalecer a capacidade de resposta do sistema de saúde. O conhecimento da cobertura assistencial intensiva pode revelar locais em que intervenções são necessárias, de modo a evitar o colapso no Sistema Único de Saúde (SUS) (Rache et al, 2020; Noronha et al, 2020; Moreira, 2020). 
Frente a suspensão do feriado de carnaval e o cenário de fevereiro de 2021, no estado de Goiás, torna-se de interesse público e científico conhecer o percentual de ocupação e a capacidade de acolhimento do sistema de saúde no período do estudo, justificando medidas mais severas de contenção ao vírus, estimando quais regiões de saúde necessitavam de medidas para diminuir a demanda do sistema de saúde. Há também, por fim, conhecer as medidas de combate à pandemia adotadas. Portanto, o objetivo do presente estudo foi realizar um recorte descrevendo o cenário de ocupação dos leitos de UTI dedicados à COVID-19 por regiões de saúde no período próximo ao carnaval, assim como as medidas adotadas para o controle da pandemia da COVID-19 no estado de Goiás.

\section{Metodologia}

A presente pesquisa trata-se de um estudo retrospectivo, observacional do tipo descritivo, no qual utilizou-se das orientações propostas por Pereira et al. (2018) do e-book intitulado Metodologia da Pesquisas Científica.

Para o entendimento sobre a sobrecarga no sistema de saúde do estado de Goiás, foram utilizadas as taxas de ocupação de leitos de UTI dedicados para COVID-19, por regiões de saúde, expostas nos mapas de risco de Goiás dos dias 17, 27 de fevereiro e 05 de março de 2021, disponíveis no Painel da COVID-19, do Portal da Secretaria de Estado da Saúde de Goiás (SES-GO) (Goiás, 2021c, 2021d, 2021e). Os dados foram coletados no dia 11 de março de 2021 e armazenados no programa Microsoft Excel para sua posterior análise, sendo que cada mapa de risco contempla os dados dos últimos sete dias.

O intervalo de tempo selecionado para a análise das taxas de ocupação de UTI iniciou em 11 de fevereiro de 2021 até 05 de março de 2021. Esse intervalo foi escolhido por conter dados durante e até duas semanas após o carnaval (16 de fevereiro de 2021) e quarta-feira de cinzas (17 de fevereiro de 2021). Sobre as regiões de saúde avaliadas no presente estudo, estão divididas em dezoito e conforme o Plano Diretor de Regionalização do estado de Goiás (Goiás, 2021f) são elas: Central, Centro Sul, Entorno Norte, Entorno Sul, Estrada de Ferro, Nordeste 1, Nordeste 2, Norte, Oeste 1, Oeste 2, Pireneus, Rio Vermelho, São Patrício 1, São Patrício 2, Serra da Mesa, Sudoeste, Sudoeste 2, Sul.

A taxa de ocupação de leitos de UTI dedicados para COVID-19, por regiões de saúde, foi calculada pela relação: ${ }^{\circ}$ de pacientes-dia (adultos) internados em leitos de UTI públicos e privados dedicados para COVID-19, nos últimos sete dias, por região de saúde $/ n^{\circ}$ de leitos de UTI-dia (adultos) para COVID-19, por região de saúde. Foram estabelecidos parâmetros de corte de forma a atribuir a situação de gravidade (Alerta: $<=0,7$; Crítica: 0,7-0,85 e Calamidade: $>=0.85$ ). Tais parâmetros foram retirados dos próprios mapas de risco.

Também, foram usados para a descrição das medidas de combate à pandemia e seus desdobramentos no estado, demais documentos estaduais (leis, decretos, portarias, resoluções e notas técnicas) retirados do Portal da SES-GO (Goiás, 2021g) e da Casa Civil de Goiás (Goiás, 2021h), disponíveis a partir de 11 de fevereiro a junho de 2021. Esses dados foram coletados no dia 5 de julho de 2021. Esta pesquisa não necessitou de aprovação em Comitê de Ética em Pesquisa por usar dados de domínio público.

\section{Resultados e Discussão}

No presente estudo, de 11 a 17 de fevereiro, intervalo de tempo que compreende o período de carnaval, as regiões de saúde Norte, Pireneus, São Patrício 1, São Patrício 2, Serra da Mesa encontravam-se em estado de alerta; as regiões Central, Centro Sul, Estrada de Ferro, Oeste 1, Oeste 2, Rio Vermelho, Sudoeste 1, Sudoeste 2, Sul em estado crítico e as do Entorno Norte, Entorno Sul, Nordeste 1, Nordeste 2 em calamidade (Figura 1). No dia 11 de fevereiro de 2021 foi decretada pela Assembleia Legislativa do estado de Goiás e sancionada a Lei no 20.967/2021, que determinava a suspenção excepcional do feriado de terça-feira de carnaval (16 de fevereiro) (Tabela 1). Tal medida foi realizada no intuito de diminuir aglomerações e 
deslocamento de pessoas para os municípios turísticos do estado, no período festivo para a redução da velocidade de propagação do novo coronavírus. Em adicional, no dia 16 de fevereiro foi emitida a Nota Técnica no 1/2021 (Tabela 1) com recomendações sanitárias aos gestores municipais de saúde sobre o controle da disseminação do vírus, a depender da situação de risco. Comparando o intervalo de tempo de 14 a 20 de fevereiro com os sete dias precedentes, anteriores ao carnaval, houve aumento de 27,3\% nos casos novos de SRAG, um total de 1.109 casos (SES-GO, 2021b). Tais achados ainda não demostram a efetividade da suspensão do feriado uma vez que o período de incubação do vírus é de 2 a 14 dias, assim o tempo desde a exposição ao vírus até o momento em que os sintomas começam é, em média, de 5 a 6 dias e pode variar de 1 a 14 dias. (WHO, 2020d), ou seja, ainda não daria tempo de parte dos indivíduos infectados, terem sintomas e procurarem serviços de saúde.

Em 17 de fevereiro, o Instituto de Assistência dos Servidores Públicos do Estado de Goiás (IPASGO) suspendeu as cirurgias eletivas para liberar leitos aos casos da COVID-19, tramite pela Portaria no 229/2021 (Tabela 1). A medida objetivou a reorganização da oferta de leitos de UTI para COVID-19. A suspensão de cirurgias eletivas presume ser uma medida transitória, apenas com o intuito de ampliar a rede hospitalar e promover mais segurança ao usuário diante de tal cenário epidemiológico.

De 21 a 27 de fevereiro de 2021, houve aumento de cerca 6\% na média das taxas de ocupação de leitos de UTI para COVID-19, em Goiás, comparado ao intervalo de 11 a 17 de fevereiro. A região de Saúde com maior aumento foi São Patrício 1, seguida pelas regiões São Patrício 2, Oeste 1 e Sul. Quatro regiões (Entorno Norte, Oeste 1, São Patrício 1 e Sul) apresentaram ocupação máxima de leitos. Houveram regiões de saúde que diminuíram as taxas de ocupação, são elas: Rio Vermelho, Oeste 2, Estrada de Ferro, Norte e Pireneus. A região Central manteve sua taxa de ocupação (Figura 2). Contudo, na última semana de fevereiro, observou-se redução de 25,7\% nos casos novos de SRAG (824 casos), em Goiás. (SES-GO, 2021c).

A mídia noticiou que apesar da proibição de eventos de carnaval por todo o Brasil, aglomerações não deixaram de acontecer em cidades como Rio de Janeiro, Natal, São Paulo, Porto Alegre, Florianópolis, entre outras (G1, 2021a). Embora a suspensão do feriado, parte da população goiana pode ter viajado e participado de eventos festivos em outros estados ou mesmo no interior do estado, contraindo o vírus. Tal cenário, pode justificar a elevação da média das taxas de ocupação de UTI posteriormente ao carnaval (Figura 2) e a preocupação entre as entidades governamentais, como a tomada de medidas de controle da transmissão do SARS-CoV-2, pelo Decreto no 9.819/2021, e recomendações da SES-GO, por meio das Notas Técnicas no 2 e 3/2021 (Tabela 1). Ainda, foi verificado no presente estudo que, no período de 21 a 27 de fevereiro, as regiões de saúde Central, Estrada de Ferro, São Patrício 2, estavam em estado crítico e as regiões Centro Sul, Entorno Norte, Entorno Sul, Nordeste 1, Nordeste 2, Oeste 1, São Patrício 1, Sudoeste 1, Sudoeste 2, Sul estavam em situação de calamidade (Figura 1). No dia 1 de março, através da Portaria no 312/2021 (Tabela 1), a SES-GO suspendeu cirurgias eletivas que possam envolver a necessidade complementar de leitos de UTI, considerado exceção os procedimentos relacionados à oncologia, cardiologia, neurologia intervencionista e neurocirurgia. 
Figura 1 - Taxa de ocupação de UTI para COVID-19 por região de saúde e a situação de gravidade, no período de 11 de fevereiro a 05 de março de 2021, no estado de Goiás.

\begin{tabular}{|c|c|c|c|}
\hline \multirow[t]{2}{*}{ Regiões de saúde } & \multicolumn{3}{|c|}{2021} \\
\hline & 11 - 17 fev. & 21 - 27 fev. & 27 fev. - 05 de mar. \\
\hline CENTRAL & 0.82 & 0.82 & 0.96 \\
\hline CENTRO SUL & 0.83 & 0.86 & 0.95 \\
\hline ENTORNO NORTE & 0.86 & 1.00 & 1.00 \\
\hline ENTORNO SUL & 0.86 & 0.86 & 0.88 \\
\hline ESTRADA DE FERRO & 0.83 & 0.73 & 0.84 \\
\hline NORDESTE 1 & 0.87 & 0.90 & 0.90 \\
\hline NORDESTE 2 & 0.86 & 0.90 & 0.90 \\
\hline NORTE & 0.46 & 0.40 & 0.30 \\
\hline OESTE 1 & 0.82 & 1.00 & 0.85 \\
\hline OESTE 2 & 0.82 & 0.68 & 0.97 \\
\hline PIRENEUS & 0.44 & 0.39 & 0.60 \\
\hline RIO VERMELHO & 0.82 & 0.62 & 0.69 \\
\hline SÃO PATRÍCIO 1 & 0.46 & 1.00 & 1.00 \\
\hline SÃO PATRÍCIO 2 & 0.46 & 0.81 & 0.89 \\
\hline SERRA DA MESA & 0.46 & 0.49 & 1.00 \\
\hline SUDOESTE 1 & 0.84 & 0.85 & 0.86 \\
\hline SUDOESTE 2 & 0.84 & 0.91 & 0.77 \\
\hline SUL & 0.83 & 1.01 & 0.97 \\
\hline
\end{tabular}

Parâmetros de corte para situação de gravidade: Alerta $<=0,7$ (amarelo); Crítica: 0,7-0,85 (laranja) e Calamidade: > = 0,85 (vermelho). Fonte: Adaptado da Secretaria de Estado da Saúde de Goiás.

O cenário preocupante a respeito da taxa de ocupação de leitos de UTI para COVID-19 em adultos não estava limitado ao estado de Goiás. No dia 2 de março, a Fundação Oswaldo Cruz (Fiocruz) divulgou seu Boletim Extraordinário demonstrando em todo o Brasil um agravamento simultâneo de diversos indicadores da COVID-19, entre eles a sobrecarga hospitalar. Nove estados, das regiões Norte, Nordeste, Centro-Oeste e Sul, tiveram taxas de ocupação de leitos de UTI superiores a 90\%. Goiás era o terceiro estado com maior taxa de ocupação de UTI para COVID-19, com 95\% de ocupação, ultrapassado apenas por Santa Catarina (99\%) e Rondônia (97\%). A própria Fiocruz apontou a preocupação trazida pelos dados em todo o Brasil e as complicações inerente a eles como a morte de pacientes devido à falta de acesso a cuidados de alta complexidade, a redução de atendimentos hospitalares por outras demandas, possível perda de qualidade na assistência e sobrecarga dos profissionais de saúde (Fiocruz, 2021a). 
Tabela 1 - Descrição dos decretos e normas do governo do estado de Goiás sobre o combate à pandemia do coronavírus, no período de 11 de fevereiro a junho de 2021.

$\begin{array}{lll}\begin{array}{l}\text { Decretos e } \\ \text { Normas }\end{array} & \text { Data } & \text { Descrição resumida }\end{array}$

\begin{tabular}{lll}
$\begin{array}{l}\text { Lei Ordinária } \\
\mathbf{n}^{\mathbf{0} 20.967}\end{array}$ & 11 de fevereiro & Dispõe sobre a suspensão do feriado da terça-feira de Carnaval no ano de 2021. \\
\hline $\begin{array}{l}\text { Nota Técnica } \\
\mathbf{n}^{\mathbf{0}} \mathbf{1 / 2 0 2 1}\end{array}$ & 16 de fevereiro & $\begin{array}{l}\text { *Situação de alerta: Funcionamento de todas as atividades, exceto eventos com mais de 150 } \\
\text { pessoas. } \\
\end{array}$ \\
& *Situação crítica: **recomendações gerais e específicas. \\
& * Situação de calamidade: Recomenda-se a interrupção de todas as atividades, exceto: \\
& supermercados e congêneres, farmácias, postos de combustível e serviços de urgência e \\
& emergência em saúde.
\end{tabular}

\begin{tabular}{lclll}
\hline $\begin{array}{l}\text { Portaria } \\
\text { 229/2021 }\end{array}$ & $\mathbf{n}^{\mathbf{0}}$ & 17 de fevereiro & $\begin{array}{l}\text { Instituto de Assistência dos Servidores Públicos do Estado de Goiás (IPASGO) suspende } \\
\text { cirurgias eletivas para liberar leitos aos casos da COVID-19. }\end{array}$ \\
\hline $\begin{array}{l}\text { Decreto } \\
\mathbf{9 . 8 1 9}\end{array}$ & $\mathbf{n}^{\mathbf{0}}$ & 27 de fevereiro & $\begin{array}{l}\text { Altera o Decreto } \mathrm{n}^{\circ} \text { 9.751, de 30 de novembro de 2020, para estabelecer o regime de } \\
\text { teletrabalho em suas unidades administrativas durante a situação de emergência em saúde } \\
\text { pública em Goiás nas entidades da administração direta, autárquica e fundacional do Poder } \\
\text { Executivo. }\end{array}$ \\
\hline $\begin{array}{l}\text { Nota Técnica } \\
\mathbf{n}^{\mathbf{0}} \mathbf{2 / 2 0 2 1}\end{array}$ & 28 de fevereiro & $\begin{array}{l}\text { *A suspensão de todos os estágios acadêmicos presenciais, em instituições públicas e privadas, } \\
\text { com e sem fins lucrativos, excetuando-se os da área da saúde para os alunos do último ano de } \\
\text { seus respectivos cursos e o internato do curso de Medicina. }\end{array}$
\end{tabular}

\begin{tabular}{lll}
$\begin{array}{l}\text { Nota Técnica } \\
\mathbf{n}^{\mathbf{0}} \mathbf{3} / \mathbf{2 0 2 1}\end{array}$ & 28 de fevereiro & Idem Nota Técnica nº $1 / 2021$ de 27 de fevereiro de 2021. \\
\hline $\begin{array}{l}\text { Portaria } \\
\text { 312/2021 }\end{array}$ & 01 de março & Suspende cirurgias eletivas que possam envolver a necessidade complementar de leitos de UTI. \\
\hline $\begin{array}{l}\text { Portaria } \\
\begin{array}{l}\text { Intersecretarial } \\
\mathbf{n}^{\mathbf{0}} \mathbf{1} / \mathbf{2 0 2 1}\end{array}\end{array}$ & 09 de março & $\begin{array}{l}\text { Criação da Comissão Transitória Intersecretarial de Acompanhamento dos Processos de } \\
\text { Aquisição e Distribuição de Vacinas para o estado de Goiás. }\end{array}$
\end{tabular}

\begin{tabular}{lll}
\hline Decreto $\mathbf{n}^{\mathbf{0}}$ & 16 de março & Dispõe sobre a retomada do revezamento das atividades econômicas no estado de Goiás que se \\
$\mathbf{9 . 8 2 8}$ & inicia com 14 dias de suspensão seguidos por 14 dias de funcionamento, sucessivamente.
\end{tabular}

\begin{tabular}{lll}
\hline $\begin{array}{l}\text { Decreto no } \\
\text { 9.829 }\end{array}$ & 16 de março & $\begin{array}{l}\text { Adota-se o sistema de revezamento das atividades presenciais na administração direta, } \\
\text { autárquica e fundacional do Poder Executivo estadual, iniciando-se com } 14 \text { dias de suspensão } \\
\text { seguidos por } 14 \text { dias de funcionamento, sucessivamente, para o enfrentamento da emergência } \\
\text { em saúde pública decorrente do coronavírus. Revogado pelo decreto } 9.856 \text { de } 29 \text { de abril de } \\
2021 .\end{array}$ \\
\hline $\begin{array}{l}\text { Resolução no } \\
\text { 030/2021 }\end{array}$ & 24 de março & $\begin{array}{l}\text { Comissão Intergestores Bipartite (CIB) - Aprova a destinação de doses (5\% do quantitativo) de } \\
\text { vacinas COVID-19 aos trabalhadores das Forças de Segurança e Salvamento no estado de } \\
\text { Goiás }\end{array}$
\end{tabular}

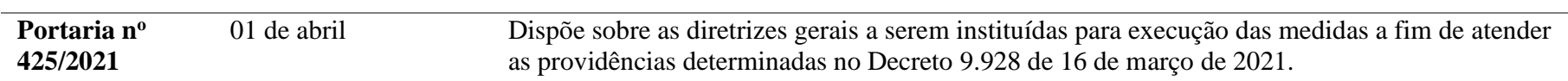

\begin{tabular}{lll}
\hline $\begin{array}{l}\text { Resolução no } \\
\text { 34/2021 }\end{array}$ & 06 de abril & $\begin{array}{l}\text { Aprova a destinação de doses (30\% do quantitativo) de vacinas COVID-19 aos profissionais e } \\
\text { trabalhadores de Saúde no estado de Goiás. }\end{array}$
\end{tabular}

\begin{tabular}{|c|c|c|}
\hline $\begin{array}{l}\text { Nota Técnica } \\
n^{0} 4 / 2021\end{array}$ & 13 de abril & $\begin{array}{l}\text { Análise técnica de tendência da evolução da COVID-19 em Goiás. Orientações escalonamento } \\
\text { de horário para atividade não essenciais e revisão dessas, se necessário; contraindicação de } \\
\text { festas e aglomerações, uso de máscara e higienização das mãos }\end{array}$ \\
\hline
\end{tabular}

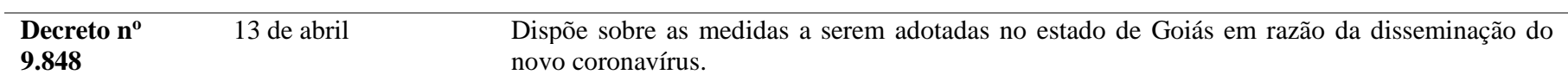

\begin{tabular}{|c|c|c|}
\hline $\begin{array}{l}\text { Nota Técnica } \\
n^{0} 5 / 2021\end{array}$ & 28 de abril & $\begin{array}{l}\text { Análise técnica de tendência da evolução da COVID-19 em Goiás. Orientações escalonamento } \\
\text { de horário para atividade não essenciais e revisão dessas se necessário, contraindicação de } \\
\text { aglomerações, uso de máscara e higienização das mãos. }\end{array}$ \\
\hline
\end{tabular}

\begin{tabular}{lll}
\hline Decreto $\mathbf{n}^{\mathbf{0}}$ & 10 de maio & Dispõe sobre a limitação de atividades na região do Rio Araguaia que impliquem em \\
$\mathbf{9 . 8 6 2}$ & & aglomeração de pessoas para o lazer e o turismo, como forma de combate à disseminação da \\
& COVID-19 no estado de Goiás. Revogado pelo Decreto n ${ }^{\circ} 9.875$ do dia 02 de junho de 2021.
\end{tabular}


Legendas: * Recomendações Sanitárias para os Gestores Municipais de Saúde; ** medidas gerais: uso de máscara de proteção respiratória e higienização das mãos, medidas específicas: ocupação em instituições religiosas (30\%), bares e restaurantes (30\%, somente entre as 6 e $22 \mathrm{~h})$, academia e quadras esportivas (50\%), salão de beleza e barbearia (50\%), funerais (até 10 pessoas), eventos (menos que 150 pessoas), empresas e escritórios (revezamento de turnos e trabalho remoto), transporte público (não exceder capacidade de passageiros sentados), escolas seguir notas técnicas estaduais, baseadas no Centro de Operações de Emergências estadual).

Fonte: Portal de Secretaria de Saúde de Goiás e do Portal da Casa Civil de Goiás.

No início do mês de março, após incremento das medidas de controle de transmissão do coronavírus, a média das taxas de ocupação em Goiás subiu em cerca 6\%. A região de saúde que apresentou o maior aumento foi a Serra da Mesa, seguida da região Oeste 2, esta que havia diminuído no período anterior; além das regiões Central e Estrada de Ferro. Regiões Nordeste 1, Nordeste 2, Entorno Norte e São Patrício 1 mantiveram as taxas, sendo que todas apresentavam valores iguais ou acima de $90 \%$ e as duas últimas continuaram apresentando capacidade máxima ocupada. Houve ocupação máxima nas duas regiões citadas acima e na Serra da Mesa totalizando três regiões. As regiões Oeste 1 e Sul saíram de 100\% de ocupação, mas continuaram em estado de calamidade com taxas de 85 e 97\%, respectivamente. Outras regiões diminuíram as taxas de ocupação de leitos de UTI para COVID-19 foram Sudoeste 2 e Norte (Figura 2). Mesmo uma semana após a determinação de medidas mais severas para contenção do novo coronavírus no estado de Goiás, as regiões de saúde em estado de calamidade aumentaram, são elas: Central, Centro Sul, Entorno Norte, Entorno Sul, Nordeste 1, Nordeste 2, Oeste 1, Oeste 2, São Patrício 1, São Patrício 2, Serra da Mesa, Sudoeste 1, Sul (Figura 1).

Dessa maneira, de 11 de fevereiro a 05 de março, a média das taxas de ocupação de leitos de UTI para COVID-19, no estado de Goiás, teve um acréscimo agregado de cerca $12 \%$. As regiões que apresentaram o maior aumento foram São Patrício 1 e Serra da mesa, seguidos por São Patrício 2. Apesar do aumento na média das taxas de ocupação, três regiões apresentaram queda de suas taxas, são elas: Norte, Rio Vermelho e Sudoeste 2. São discrepantes do restante do estudo os resultados, no mesmo período, encontrados na região Norte. Além de ter sido encontrada uma evolução decrescente da taxa de ocupação de leitos de UTI, essa foi a única região de saúde em que os valores foram menores que 40\% (Figura 2). Seria de interesse público e científico a realização de estudos mais detalhados nessa região para compreender a causa desses resultados para a formulação de políticas públicas e medidas sanitárias para o melhor enfrentamento da pandemia. 
Research, Society and Development, v. 10, n. 12, e272101220292, 2021

(CC BY 4.0) | ISSN 2525-3409 | DOI: http://dx.doi.org/10.33448/rsd-v10i12.20292

Figura 2 - Evolução das taxas de ocupação de UTI para COVID-19 no período de 10 de fevereiro a 05 de março de 2021 , no estado de Goiás.

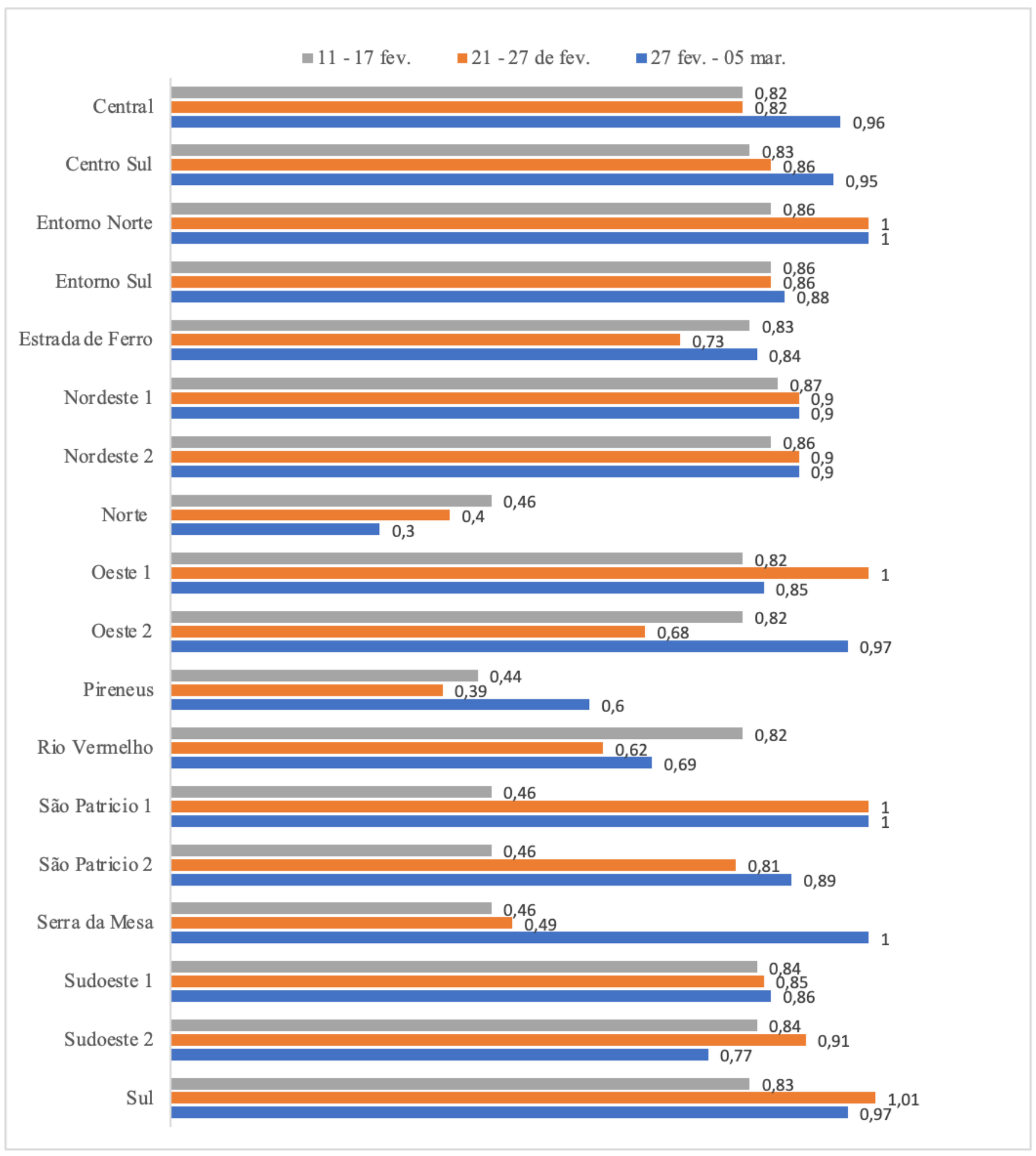

Fonte: Secretaria de Estado da Saúde de Goiás.

No dia 09 de março, pela Portaria no 1/2021 (Tabela 1), houve a criação da Comissão Transitória Intersecretarial de Acompanhamento dos Processos de Aquisição e Distribuição de Vacinas para o estado de Goiás. Tornou-se de competência da comissão a contribuição com todos os processos de aquisição, logística e distribuição de vacinas contra a COVID-19. Ocorreu aumento na distribuição e aplicação de vacinas para os munícipios do estado, em março. Enquanto, desde o início do ano ao 
final de fevereiro, foram distribuídas 278.420 e aplicadas 231.858 primeiras doses, distribuídas 210.414 e aplicadas 69.500 segundas doses às regiões de saúde do estado. Em março foram distribuídas 468.826 e aplicadas 425.289 primeiras doses, distribuídas 90.650 e aplicadas 88.738 segundas doses. Esse aumento se deve principalmente pelo incremento majestoso na distribuição de primeiras doses no final do mês (Goiás, 2021i, 2021j). Ao observar a incidência de casos novos de SRAG no estado, em março, nota-se aumento semanal até o dia 27, registrando uma incidência de 1.943 no período de 21 a 27 de março (SES-GO, 2021d, 2021e, 2021f, 2021g). Do dia 28 de março a 03 de abril, houve queda na incidência de SRAG de 19,1\%, totalizando 1.571 casos (SES-GO, 2021h).

Apesar da implementação da vacinação em todo o Brasil (da Paz Silva Filho et al, 2021), o incremento da vacinação no estado e os Decretos no 9.828/2021 e 9.829/2021 (Tabela 1), a mídia indicou o mês de março como o pior mês da pandemia até então, em Goiás, e deram como explicação para dados tão negativos no estado a descoberta da variante brasileira P.1, em fevereiro (G1, 2021b). Esta variante foi encontrada pela primeira vez no Japão em quatro viajantes provenientes de Manaus e foi notificada no dia 09 de janeiro de 2021, por autoridades locais à OMS (Fujino et al, 2021). A variante P.1 está ligada a maior virulência e aumento da mortalidade e casos de SRAG, mesmo em pacientes sem morbidades prévias e mais jovens (Freitas et al, 2021).

No dia 01 de abril, a Portaria no 425/2021 (Tabela 1) reitera a situação de emergência no estado de Goiás, adotando ações de distanciamento social conforme a situação de risco de cada região de saúde. Na primeira quinzena de abril a incidência de casos de SRAG, em Goiás, continuou a subir. De 04 a 10 de abril foram notificados 2.027 casos (aumento de $29 \%$ ) e de 11 a 17 de abril foram 2.166 casos (aumento de 6,9\%), comparado às respectivas semanas anteriores (SES-GO, 2021i, 2021j). A Nota Técnica no 04/2021 (Tabela 1), publicada dia 13 de abril, analisa indicadores desde 17 de março até sua data de publicação. Ela traz que apesar da incidência de SRAG ter queda em uma região, estabilização em oito e subida em nove regiões, tal indicador, dada a sazonalidade de outras patologias respiratórias agudas, deve ser analisado de forma contextualizada e não isolada. A referida Nota Técnica apontou que: a velocidade de contágio do dia 07 de abril diminuiu em quatro regiões de saúde e se estabilizou nas demais regiões; no dia 11 de abril a incidência de solicitações de leito ao Complexo Regulador Estadual (CRE) teve o menor número de solicitações desde a segunda onda; a variação de mortalidade apresentou queda em todas as regiões de saúde, exceto Nordeste 2; e a tendência de estabilização na taxa de ocupação de leitos de UTI estaduais. Todavia, na segunda quinzena de abril, houve queda na incidência de casos de SRAG, isto é, de 18 a 24 de abril diminuição em 23,3\% (1.662 casos) e de 25 de abril a 01 de maio em 7,3 \% (1.541 casos), comparando com as respectivas semanas anteriores (SES-GO, 2021k, 20211).

De 02 a 08 de maio, houve queda de 13\% na incidência de casos de SRAG, comparando com a semana anterior, totalizando 1.341 novos casos (SES-GO, 2021m). Até o final do mês, foram aplicadas 539.806 primeiras doses e 127.181 segundas doses de vacinas contra a COVID-19, em Goiás. Já, em junho, foram aplicadas 858.176 primeiras doses e 102.876 segundas dose de vacina contra a COVID-19 (Goiás, 2021j). Pelo Boletim InfoGripe da semana epidemiológica 25 (20 a 26 de junho), em 2021 até o momento de sua publicação, ocorreram 500.377 casos de SRAG sendo cerca de 96\% desses causados pelo SARS-CoV-2 (Fiocruz, 2021b). Pelo Boletim Extraordinário da Fiocruz de 30 de junho de 2021, do dia 21 a dia 28 de junho, houve queda na taxa de ocupação de leitos de UTI dedicados à COVID-19 de pelo menos cinco pontos percentuais em dez estados da federação. Segundo a Fiocruz, apenas três estados encontravam-se com taxa de ocupação de leitos de UTI para COVID-19 superior ou igual a 90\%, eram eles Tocantins (90\%), Paraná (94\%) e Santa Catarina (92\%). O estado de Goiás se encontrava como o sétimo estado com maior taxa de ocupação, sendo essa 85\% (Fiocruz, 2021c).

É importante ressaltar que essa pesquisa foi realizada mediante dados secundários dos sistemas de informação em saúde no Brasil, esses que vem sendo utilizados em diversos estudos epidemiológicos, mas podem apresentar problemas na qualidade e integridade apesar do empenho das entidades públicas. Outra limitação do presente estudo é que cada munícipio do 
estado de Goiás, por sua vez, pode ou não ter aderido as recomendações da SES-GO, além de ter emitido documentos não disponíveis no Portal da SES-GO e da Casa Civil de Goiás.

\section{Conclusão}

Percebe-se que apesar das medidas de contenção da transmissão do SARS-CoV-2, no período de 11 de fevereiro a 05 de março houve aumento nas taxas de ocupação de leitos de UTI na maioria das regiões de saúde do estado de Goiás.

Entre as medidas usadas para o controle da transmissão do SARS-CoV-2 de 11 de fevereiro a junho de 2021, nota-se a suspensão do feriado de carnaval para tentar evitar aglomerações; notas técnicas, decretos e portarias com o propósito de distanciamento físico, através de: teletrabalho, estabelecimento de ocupação máxima em locais fechados e em eventos, escalonamento de horários ou interrupção de serviços não essenciais, suspensão de estágios acadêmicos, entre outros; realocação de leitos, através da suspensão de cirurgias eletivas para liberá-los aos casos da COVID-19; higienização das mãos; o uso de máscara; e a criação da Comissão Transitória Intersecretarial de Acompanhamento dos Processos de Aquisição e Distribuição de Vacinas para acelerar e otimizar a vacinação, em Goiás.

O presente estudo é pertinente no contexto atual de pandemia devido ao número de casos de SRAG ocorridos pelo SARS-CoV-2 no estado de Goiás, à grande relevância na mídia, aos inúmeros esforços humanos e financeiros por entidades públicas e privadas no controle do novo coronavírus. Por fim, são necessários estudos analíticos que investiguem de forma detalhada cada medida de controle comparando-as com a incidência de novos casos de SRAG pelo SARS-CoV-2, para demonstrar as de maior efetividade, bem como orientar na otimização do controle na transmissão do vírus.

\section{Referências}

Brasil. Ministério da Saúde. Secretaria de Vigilância em Saúde (2019). Departamento de Análise em Saúde e Doenças não Transmissíveis. Guia de Vigilância Epidemiológica: emergência de saúde públicas de importância nacional pela doença pelo coronavírus 2019. Brasília, 2021a.

Brasil. Ministério da Saúde. Secretaria de Vigilância em Saúde. Departamento de Vigilância das Doenças Transmissíveis. Protocolo de tratamento de influenza: 2017. 2018. 18 p b.

Freitas, A. R. R., Beckedorff, O. A., Cavalcanti, L. P. de G., Siqueira, A. M., Castro, D. B. de, Costa, C. F., Barros, E. N. C. (2021). A emergência da nova variante P.1 do SARS-CoV-2 no Amazonas (Brasil) foi temporalmente associada a uma mudança no perfil da mortalidade devido a COVID-19, segundo sexo e idade. Scielo Preprints, 1-20. https://doi.org/10.1590/SciELOPreprints.2030

Fujino, T., Nomoto, H., Kutsuna, S., Ujiie, M., Suzuki, T., Sato, R., Fujimoto, T., Kuroda, M., Wakita, T., \& Ohmagari, N. (2021). Novel SARS-CoV-2 Variant in Travelers from Brazil to Japan. Emerging infectious diseases, 27(4), 1243-1245.

Fundação Oswaldo Cruz. Boletim Observatório COVID-19. Rio de Janeiro: FIOCRUZ, (2021). https://portal.fiocruz.br/sites/portal.fiocr uz.br/files/documentos/boletim_extraordinario_2021-marco-03.pdf.

Fundação Oswaldo Cruz. Boletim Observatório COVID-19. Rio de Janeiro: FIOCRUZ, (2021 (2021). https://agencia.fiocruz.br/sites/agencia.fiocruz. br/files/u34/resumo_infogripe_2021_25.pdf.

G1. Apesar de proibição de eventos de carnaval, aglomerações são registradas em várias partes do país. 14 fev. 2021. (2021) https://g1.globo.com/bemestar/coronavirus/noticia/2021/02/14/apesar-de-proibicao-de-eventos-de-carnaval-aglomeracoes-sao-registradas-em-varias-partes-dopais.ghtml.

G1. Pior mês da pandemia, março teve por dia 98 mortes e mais de 2,8 mil casos de COVID-19 em Goiás. 31 mar. 2021. (2021) https://g1.globo.com/go/goias/noticia/2021/03/31/pior-mes-da-pandemia-marco-teve-por-dia-98-mortes-e-mais-de-28-mil-casos-de-covid-19-em-goias.ghtml.

Goiás (Estado). Casa Civil. Conheça os decretos e normas do governo de Goiás sobre o combate à pandemia do coronavírus. (2020-2021). https://www.casacivil.go.gov.br/noticias/9033-legislação-sobre-o-coronav\%C3\%ADrus-covid-19.html.

Goiás (Estado). Casa Civil. Suspensão do feriado de terça-feira de carnaval em 2021 é aprovada pela Assembleia Legislativa. (2021). https://www.casacivil.go.gov.br/noticias/9240-suspensão-do-feriado-de-terça-feira-de-carnaval-em-2021-é-aprovada-pela-assembleia-legislativa.html.

Goiás (Estado). Secretaria de Estado da Saúde. Coronavírus - Notas Técnicas e Informativas. (2020-2021). https://www.saude.go.gov.br/coronavirus/notastecnicas-e-informativas. Acesso em: 05 jul. 2021g.

Goiás (Estado). Secretaria de Estado da Saúde. Doses distribuídas por município. (2021). https://www.saude.go.gov.br/coronavirus/vacinacao-covid-19/dosesdistribuidas. Acesso em: 05 jul. 2021 i. 
Research, Society and Development, v. 10, n. 12, e272101220292, 2021 (CC BY 4.0) | ISSN 2525-3409 | DOI: http://dx.doi.org/10.33448/rsd-v10i12.20292

Goiás (Estado). Secretaria de Estado da Saúde. Mapa de Risco - 05/03/ 2021. mar. 2021. https://datasets.saude.go.gov.br/docs/coronavir us/mapa_de_risco_05mar2021.pdf. Acesso em 11 mar. 2021e.

Goiás (Estado). Secretaria de Estado da Saúde. Mapa de Risco - 17/02/2021. fev. 2021. https://datasets.saude.go.gov.br/docs/coronavi rus/mapa_de_risco_17fev2021.pdf. Acesso em 11 mar. 2021c.

Goiás (Estado). Secretaria de Estado da Saúde. Mapa de Risco - 27/02/2021. fev. 2021. https://datasets.saude.go.gov.br/docs/coronavir us/mapa_de_risco_27fev2021.pdf. Acesso em 11 mar. 2021d.

Goiás (Estado). Secretaria de Estado da Saúde. Quantidade de doses aplicadas por semana da epidemiológica. [2021]. Gráfico. https://indicadores.saude.go.gov.br/pentaho/api/repos/:coronavirus:paineis:painel.wcdf/generatedContent. Acesso em: 21 jul. $2021 \mathrm{j}$.

Goiás (Estado). Secretaria de Estado da Saúde. Regionais de saúde. [2021]. https://www.saude.go.gov.br/unidades-de-saude/regioes-de-saude. Acesso em: 22 jul. 2021f.

Goiás (Estado). Secretaria de Estado da Saúde. Superintendência do Complexo Regulador em Saúde de Goiás. Protocolo de Regulação de Internação e de Urgência e Emergência - COVID-19. Goiás, 2021. https://www.saude.go.gov.br/files/regulacao_estadual/protocoloderegulacao.pdf. Acesso em: 30 jun. 2021b.

Moreira, R. da S. (2020). COVID-19: unidades de terapia intensiva, ventiladores mecânicos e perfis latentes de mortalidade associados à letalidade no Brasil. Cadernos de Saúde Pública, 36(5). https://doi.org/10.1590/0102-311x00080020

Noronha, K. V. M. de S., Guedes, G. R., Turra, C. M., Andrade, M. V., Botega, L., Nogueira, D., \& Ferreira, M. F. (2020). Pandemia por COVID-19 no Brasil: análise da demanda e da oferta de leitos hospitalares e equipamentos de ventilação assistida segundo diferentes cenários. Cadernos de Saúde Pública, 36(6). https://doi.org/10.1590/0102-311x00115320

Paz Silva Filho, P. S., Sousa Silva, M. J., Júnior, E. J. F., Rocha, M. M. L., Araújo, I. A., de Carvalho, I. C. S., \& Mesquita, G. V. (2021). Vacinas contra Coronavírus (COVID-19; SARS-COV-2) no Brasil: um panorama geral. Research, Society and Development, 10(8), e26310817189-e26310817189.

Pereira, A. S., Shitsuka, D. M., Parreira, F. J., \& Shitsuka, R. (2018). Metodologia da Pesquisa Científica. UFSM.

Rache B., Rocha, R., Nunes, L., Spinola, P., Malik, A. M. \& Massuda A. (2020). Necessidades de Infraestrutura do SUS em Preparo ao COVID-19: Leitos de UTI, Respiradores e Ocupação Hospitalar. Nota Técnica n.3. IEPS

Secretaria de Estado da Saúde (Goiás). Boletim Epidemiológico COVID-19 (2021). [n. 46, 19 fev.a; n. 47, 26 fev.b; n. 48, 05 mar.c; n. 49, 12 mar.d; n. 50, 19 mar.e; n. 51, 26 mar.f; n. 52, 02 abr.g; n. 53, 09 abr.h; n. 54, 16 abr.i; n. 55, 23 abr.j; n. 56, 30 abr.k; n. 57, 07 mai.1; n. 58, 14 mai.m]. https://www.saude.go.gov.br/boletins-e-informes.

World Health Organization (WHO). Coronavirus disease (COVID-19). (2020). https://www.who.int/emergencies/diseases/novel-coronavirus-2019/questionand-answers-hub/q-a-detail/coronavirus-disease-covid-19.

World Health Organization (WHO). Coronavírus disease 2019 (COVID-19): situation report - 1. 21 jan. 2020. <https://www.who.int/docs/defaultsource/coronaviruse/situation-reports/20200121-sitrep-1-2019-ncov.pdf>.

World Health Organization (WHO). Novel Coronavírus (2019-nCov): situation report - 11. 31 jan. 2020. <https://apps.who.int/iris/bitstream/handle/ 10665/330776/nCoVsitrep31Jan2020-eng.pdf?sequence=1\&isAllowed=y>.

World Health Organization (WHO). Novel Coronavírus (2019-nCov): situation report - 51. 11 mar. 2020. <https://www.who.int/docs/defaultsource/coronaviruse/situation-reports/20200311-sitrep-51-covid-19.pdf>. 